University of Nebraska - Lincoln

DigitalCommons@University of Nebraska - Lincoln

Faculty Publications, Department of Psychology

Psychology, Department of

September 2004

\title{
Extending the role of associative learning processes in nicotine addiction.
}

Rick A. Bevins

University of Nebraska-Lincoln, rbevins1@unl.edu

Matthew I. Palmatier

University of Pittsburgh, mip16@pitt.edu

Follow this and additional works at: https://digitalcommons.unl.edu/psychfacpub

Part of the Psychiatry and Psychology Commons

Bevins, Rick A. and Palmatier, Matthew I., "Extending the role of associative learning processes in nicotine addiction." (2004). Faculty Publications, Department of Psychology. 17.

https://digitalcommons.unl.edu/psychfacpub/17

This Article is brought to you for free and open access by the Psychology, Department of at DigitalCommons@University of Nebraska - Lincoln. It has been accepted for inclusion in Faculty Publications, Department of Psychology by an authorized administrator of DigitalCommons@University of Nebraska - Lincoln. 


\title{
Extending the Role of Associative Learning Processes in Nicotine Addiction
}

\author{
Rick A. Bevins \\ University of Nebraska-Lincoln \\ Matthew I. Palmatier \\ University of Pittsburgh
}

Compulsive smoking is a worldwide public health problem. Although research has confirmed the importance of associative learning processes in nicotine addiction, therapies targeting nicotine-associated cues still have a high relapse rate. Most theories conceptualize nicotine as an 'outcome' that reinforces behaviors and/or changes the affective value of stimuli. Albeit important, this view does not capture the complexity of associative processes involved in nicotine addiction. For example, nicotine serves as a conditional stimulus acquiring new appetitivelaffective properties when paired with a non-drug reward. Also, nicotine functions as an occasion setter that participates in higher-order associative processes that likely permit a more pervasive influence of conditioned cues that are resistant to typically cue-exposure therapy techniques. Finally, nicotine appears to amplify the salience of other stimuli that have some incentive value resulting in enhanced nicotine self-administration and conditioned reinforcement processes. Future smoking intervention strategies should take into consideration these additional associative learning processes.

Key Words: Drug abuse; Pavlovian conditioning; Smoking; Tobacco

\section{TOBACCO USE: HEALTH AND ECONOMIC IMPACT}

With an estimated $23 \%$ of the adult population in the United States classified as smokers, tobacco use is considered one of the leading causes of preventable deaths in the Unit-

ed States (Centers for Disease Control [CDC], n.d.). The consensus among the scientific community is that nicotine is the main additive compound in tobacco products. Nicotine addiction results in the consumption of more than 400 billion cigarettes a year (Federal Trade Commission, 2001), with the CDC estimating that this consumption kills nearly 440,000 people, resulting in a loss of more than $\$ 50$ billion a year in health-related expenses and lost worker productivity due to early deaths. Clearly, chronic tobacco use is costly from an individual and societal perspective. The health and economic benefits of quitting are enormous. Indeed, the potential savings would be even more substantial if the long-term abstinence rates were high. Smokers seem motivated to quit, and a majority (about 70\%) express a desire to quit. Unfortunately, of those individuals that manage to quit smoking, about $95 \%$ relapse within a year (Garret, Rose, \& Henningfield, 2001). The success rate can be increased to varying degrees with behavioral (e.g., counseling, cue-exposure therapy) and pharmacological (nicotine replacement, Zyban) interventions (Glover \& Glover, 2001; Hughes, Goldstein, Hurt, \& Shiffman, 1999; Swan et al., 2003). There is little doubt of the potential benefits that could come from research leading to a better understanding of the etiology of tobacco dependence. This understanding will likely require a multifaceted approach in which genetic, neurobiological, individual, and cultural factors are considered (Carmody, 1990; Conners et al., 1996; Emmons, Wechsler, Dowdall, \& Abraham, 1998; Fisher, Lichtenstein, Haire-Joshu, Morgan, \& Rehberg, 1993; Henningfield, Schuh, \& Jarvik, 1995; Koob, 2004; Tomar \& Giovino, 1998; Tyndale \& Sellers, 2001).

\footnotetext{
Authors' Note: Some of the research described in this report was supported by United States Public Health Service Grants DAII893, DAI8I I4, and DAI6179 and funds from the Nebraska Department of Health and Human Services and the University of Nebraska Research Council.We extend our thanks to Dawn Metschke for her technical assistance and to Chana Akins, Eric Donny, Jennifer Murray, and Jamie Wilkinson for their thoughtful comments on an earlier version of this article. Address correspondence to Rick A. Bevins, Department of Psychology, University of Nebraska-Lincoln, Lincoln, NE 68588-0308; email: rbevins I@unl.edu.
} 


\section{TOBACCO USE AND ASSOCIATIVE LEARNING-BASED INTERVENTIONS}

Of interest in the present review is recent preclinical laboratory research on associative learning processes and its potential implications for nicotine addiction and the development of more effective intervention strategies. However, before discussing this research, we should provide a broader context in which to think about these advances. To this end, in this section we briefly describe the prevalent conceptualization of how associative learning processes contribute to chronic tobacco use and how this conceptualization has informed intervention strategies. Pavlovian (classical) conditioning research has provided an important procedural and theoretical framework in which to conceptualize associative learning processes in drug abuse. In a typical Pavlovian conditioning procedure, one stimulus (conditional stimulus [CS]) is presented repeatedly and in close temporal proximity to another stimulus (unconditioned stimulus [US]). Conditioning is evidenced when responding to the CS is modified relative to a control value (Pavlov, 1927; Wasserman \& Miller, 1997). The acquired response evoked by the CS is typically referred to as a conditioned response (CR). For a typical smoker, potential CSs include cigarette pack, throat irritation, taste and odor of cigarettes, and/or situational cues such as a smoking area or car (Geier, Mucha, \& Pauli, 2000; Lazev, Herzog, \& Brandon, 1999; Pritchard, Robinson, Guy, Davis, \& Stiles, 1996; Rose, Behm, \& Levin, 1993; Rose \& Levin, 1991). Nicotine and its central nervous system (CNS) effects are the US (see later for a more detailed discussion). A recent study by Lazev et al. (1999) with young adult male and female smokers provides a good exemplar. Participants had a complex polymodal stimulus that included a visual, auditory, and olfactory component paired with access to smoking their preferred brand of cigarette. The polymodal stimulus was considered the CS, and all associated exteroceptive and interoceptive stimulus events associated with smoking the cigarette were considered the US. With repeated CS-US pairings, the CS alone (i.e., before access to cigarette) evoked an increase in pulse rate and Likert-type scale report of "urge/craving to smoke." More important, this change was not observed to a second polymodal stimulus that was never paired with access to a cigarette. The authors took this differential control of urges and pulse rate as evidence for a conditioned association between the polymodal CS and smoking.

Cue-exposure approaches to the treatment of drug dependence reflect the translation of laboratory research and theory in Pavlovian conditioning into drug abuse intervention techniques (Carter \& Tiffany, 1999; Dadds, Bovb- jerg, Redd, \& Cutmore, 1997; Niaura et al., 1999; O’Brien, Childress, McLellan, \& Ehrman, 1992; Siegel \& Ramos, 2002). This approach to smoking cessation might include a combination of exposure to the actual smoking-related stimuli (e.g., smell and touch of a cigarette) and slides or imagery of high-risk smoking situations (cf. Niaura et al., 1999; see Lee et al., 2003 for the potential use of virtual reality). A main assumption behind cue-exposure therapies is that repeated exposure to smoking-related stimuli (CSs) will decrease their ability to evoke smoking-related CRs (e.g., urges, craving, withdrawal, seeking, etc.). As stated by Niaura et al. (1999), "Cue exposure was presented as a method for breaking the bond between smoking triggers and urges" (p. 688). Laboratory research on extinction of Pavlovian conditioning supports the basic premise of this approach. That is, repeated presentation of an excitatory CS without the US (i.e., extinction) typically results in a systematic decrease in the CS-evoked CR (Bevins, Jensen, Hinze, \& Besheer, 1999; Pavlov, 1927; Wasserman \& Miller, 1997).

Although extinction clearly decreases the $\mathrm{CR}$, from an intervention perspective, it is important to note that current research indicates that this loss in CR does not reflect a destruction of the CS-US association or a "breaking" of a bond. Rather, loss of conditioned responding appears to result from a competing learning history (association) that prevents expression of the CR (Bouton, 1991; Brooks \& Bouton, 1993; Pavlov, 1927; Robbins, 1990). Notably, this competing learning tends to be situation specific (e.g., Bouton, 1991, 2002). Experiments observing this effect generally proceed as follows: A CS is paired with the US in one distinct environment (Context A). Once a robust CR has developed, the same CS is then extinguished (no US) in a second environment (Context $\mathrm{B}$ ). When extinction is complete (i.e., no CR), the CS is then tested back in Context $\mathrm{A}$ or in a third distinct environment. In either test, the CS regains its ability to evoke the $\mathrm{CR}$, indicating that extinction did not destroy the CS-US association. An implication of this research is that cue-exposure therapy might be limited in its effectiveness given that the conditional stimuli or "smoking triggers" are typically presented in the clinical setting. Although there are many demonstrated successes of cue exposure in the treatment of drug dependence, there are also demonstrations that, relative to (or in addition to) other intervention approaches, cue exposure does not improve intervention success for smoking (e.g., Niaura et al., 1999; Raw \& Russell, 1980). Attention to the context specificity of extinction might improve the success rate of cue-exposure approaches (see Bouton, 2002, and Siegel \& Ramos, 2002, for recent and more detailed discussions of these issues). 


\section{ASSOCIATIVE LEARNING: NICOTINE ASTHE US}

A majority of the preclinical research in this area (see Table 1) mirrors the laboratory and clinical research with humans and smoking just discussed in that nicotine is procedurally conceptualized as the US; the CS is an exteroceptive stimulus that reliably co-occurs with nicotine. A detailed discussion of each model in Table 1 is beyond the scope and goal of this review. Rather, we will summarize some of the research from one of the more widely studied models, locomotor conditioning, and discuss what these recent findings suggest for associative learning-based approaches to smoking cessation.

Take as an example one of the first demonstrations of locomotor conditioning from our laboratory (see Experiment 1 of Bevins, Besheer, \& Pickett, 2001). In

that experiment, each rat had a distinct circular white chamber (i.e., a context CS) paired on eight separate occasions with a subcutaneous (SC) injection of nicotine (0.42 $\mathrm{mg} / \mathrm{kg}$ base, or $1.2 \mathrm{mg} / \mathrm{kg}$ salt form). Each 30 -minute conditioning session (context CS - nicotine US pairing) was separated by 24 hours, and nicotine was administered immediately upon placement in the chamber. Unpaired controls received similar exposure to the context CS and nicotine US but in a temporally separated fashion. On the test day, both sets of rats (paired and unpaired) were injected with saline and exposed immediately to the context CS. This drug-free test lasted 30 minutes, and activity, defined as the number of infrared beam breaks, was automatically recorded throughout the test session. As shown in Figure 1 , rats that had the context CS paired with nicotine were more active than control rats. This context-evoked increase in activity was maintained throughout the drug-free test. Walter and Kuschinsky (1989) have reported a similar conditioned increase in sniffing and rearing (see also Schroeder, Binzak, \& Kelley, 2001). We, and others, have taken this selective increase in activity to reflect a conditioned association between the context CS and the psychomotor effects of the nicotine US (e.g., Bevins et al., 2001; Dwoskin, Crooks, Teng, Green, \& Bardo, 1999; Walter \& Kuschinsky, 1989).

Many theories of drug addiction invoke the development of conditioned associations through repeated drug experience to explain acquisition, maintenance, and/or relapse of compulsive drug-taking behavior (e.g., DiChiara, 1995; Koob, 2004; O’Brien et al., 1992; Robinson \& Berridge, 1993; Siegel \& Ramos, 2002; Stewart, 2004; Wise \& Bozarth, 1987). The incentive-sensitization theory of addiction proposed by Robinson and Berridge (1993; see also Berridge \& Robinson, 2003) is of direct import to the observation of nicotine-conditioned hyperactivity. A central component to this theory is that conditioned associations between environmental stimuli and the CNS effects of a drug result in increased drug seeking and taking. That is, the incentive salience induced by the drug US becomes associated with contiguous environmental cues (CSs). Because a conditioned association develops over multiple drug exposures, the incentive salience of the drug is enhanced (sensitized). Furthermore, this association means that the CS has become an incentive that can access these drug-sensitized neurobiological processes thus evoking cravings, "drug wanting," and approach to drug-related situations. In the words of Robinson and Berridge (1993),

Thus, with repeated drug use the act of drug taking and
drug-associated stimuli, gradually become more and more
attractive. Drug-associated stimuli become more and
more able to control behavior, because the neural system
that mediates "wanting" becomes progressively sensitized.
"Wanting" evolves into obsessive craving and this is man-
ifest behaviorally as compulsive drug seeking and drug
taking. Therefore, by this view, drug craving and addictive
behavior are due specifically to sensitization of incentive
salience. (p. 249)

Table 1: Preclinical Models for Studying Associative Learning With Nicotine as the US

\begin{tabular}{|c|c|c|c|}
\hline Model & $\begin{array}{l}\text { Conditional } \\
\text { Stimulus }\end{array}$ & $\begin{array}{l}\text { Behavior Change } \\
\text { (Conditioned Response) }\end{array}$ & Example References \\
\hline Conditioned anxiety & Contextual cues & $\begin{array}{l}\text { Avoidance of open arms in elevated plus } \\
\text { maze }\end{array}$ & $\begin{array}{l}\text { File, Cheeta, Irvine, Tucci, and Akthar } \\
\quad(2002) \text {; Tucci, Cheeta, Genn, Seth, and } \\
\text { File (2002) }\end{array}$ \\
\hline Conditioned taste avoidance & Flavored solution & $\begin{array}{l}\text { Decrease in consumption and increase in } \\
\text { chin rubs and gapes }\end{array}$ & $\begin{array}{l}\text { Iwamoto and Williamson (1984); Parker } \\
\text { (1995) }\end{array}$ \\
\hline Conditioned tolerance & Contextual cues & $\begin{array}{l}\text { Altered analgesic response and corticos- } \\
\text { terone levels }\end{array}$ & $\begin{array}{l}\text { Caggiula et al. (1991); Epstein, Caggiula, } \\
\text { and Stiller (1989) }\end{array}$ \\
\hline Place conditioning & Contextual cues & $\begin{array}{l}\text { Approach/avoidance of paired environ- } \\
\text { ment (context) }\end{array}$ & $\begin{array}{l}\text { Fudala and Iwamoto (1986); Shoaib, } \\
\text { Stolerman, and Kumar (1994) }\end{array}$ \\
\hline Locomotor conditioning & Contextual cues & $\begin{array}{l}\text { Increase in general activity, sniffing, and } \\
\text { rearing }\end{array}$ & $\begin{array}{l}\text { Bevins, Besheer, and Pickett (2001); } \\
\text { Walter and Kuschinsky (1989) }\end{array}$ \\
\hline
\end{tabular}


At the time Robinson and Berridge published this incentive-sensitization theory, there was only a single demonstration of conditioned locomotor sensitization with nicotine (Walter \& Kuschinsky, 1989). Accordingly, they relied on evidence from locomotor conditioning research with cocaine, amphetamine, and morphine to support their theory. Since then, the effect with nicotine has been observed in multiple laboratories, a few of the functional relations at the behavioral level have been described, and some of the neurobiological processes involved in the expression of the conditioned association have been identified. Whether this nicotine-conditioned hyperactivity provides an indirect measure of sensitized incentive salience can still be debated (cf. Wise \& Bozarth, 1987), but the findings summarized in the remaining paragraphs of this section are consistent with the theory.

Nicotine-conditioned hyperactivity has been demonstrated in 6 different laboratories using a range of conditioning parameters (Bevins et al., 2001; Dwoskin et al., 1999; Le Foll, Schwartz, \& Sokoloff, 2003; Reid, Ho, \& Berger, 1996; Schroeder et al., 2001; Walter \& Kuschinsky, 1989). For example, this research has used between 5 to 15 conditioning trials (context CS $\cdot$ nicotine US pairings), with trial durations (time in chamber) ranging from

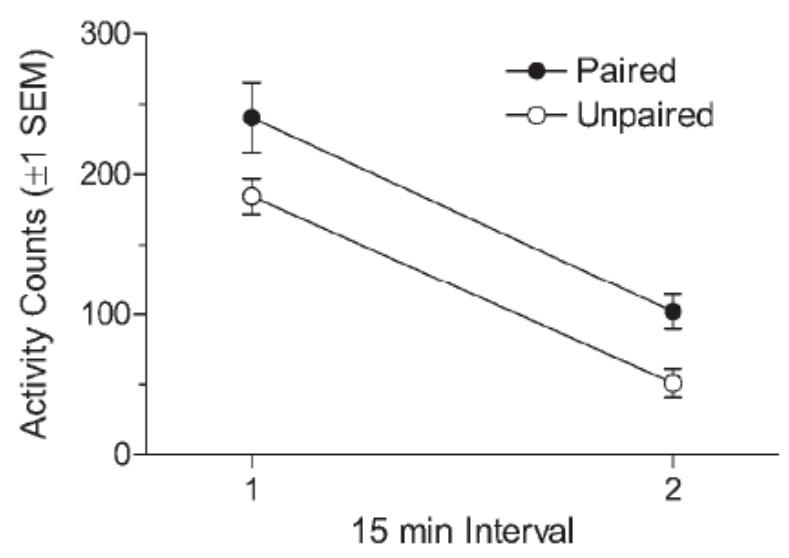

Figure 1: Mean Activity Level for Nicotine Paired and Unpaired Rats in a Drug-Free Test for Locomotor Conditioning

NOTE: There was a main effect of group, $F(1,26)=9.32, p=005$, and of interval, $F(1,26)=87.83, p<.001$, but no significant interaction, $F<1$, indicating that the paired rats were consistently more active than the unpaired control rats (i.e., nicotine-conditioned hyperactivity). Data in the graph were previously published in a different form (Bevins et al., 2001; Experiment 1, groups unpaired and 1.2 nic).
30 to 90 minutes and the effective dose of nicotine (US intensity) varying from 0.21 to $0.6 \mathrm{mg} / \mathrm{kg}$ free base, injected SC. In our laboratory, pairing an environment CS with lower doses of nicotine (i.e., 0.11 to $0.18 \mathrm{mg} / \mathrm{kg}$ ) does not result in conditioned hyperactivity (Bevins \& Palmatier, 2003; Palmatier, Fung, \& Bevins, 2003). Notably, these doses have perceptible stimulus effects in rodents as measured by the drug's ability to serve as a cue to guide behavior in a drug discrimination task (e.g., Stolerman, Garcha, Pratt, \& Kumar, 1984; see the next section for a more detailed discussion). Given this research, the absence of conditioning at these doses cannot reflect the lack of perceptible stimulus effects. More likely, the lack of locomotor conditioning reflects the fact that these doses have weak to no psychomotor stimulant effects. That is, the unconditioned response (UR) is too weak to maintain a conditioned association. If rats are preexposed to $0.18 \mathrm{mg} / \mathrm{kg}$ dose of nicotine for 3 or 9 days, the subsequent stimulant effects of this dose of nicotine are potentiated (sensitized) and hence able to condition hyperactivity to a context CS (Bevins \& Palmatier, 2003).

This preexposure result suggests that the US in locomotor conditioning studies might be better conceptualized as the UR (behavioral activation) rather than simply the dose of the drug being administered. This suggestion is consistent with a recent theoretical model of learning that emphasizes the importance of the temporal relation between the CS and UR evoked by the US (Donahoe \& Vegas, 2004). In contrast, typical research and theory on associative learning emphasize the temporal relation between the CS and US (Pavlov, 1927; Wasserman \& Miller, 1997). Indeed, much of associative learning theory is built on the assumption of stimulus-stimulus associations. It is important to note, however, that presentation of the US usually results in the occurrence of the UR in close temporal proximity (i.e., US and UR occurrence confounded; but see Donahoe \& Vegas, 2004). We are not suggesting that associative learning processes involved in tobacco addiction do not include stimulus-stimulus associations. Rather, we are suggesting that thinking about the relevance of the UR to drug conditioning and to designing experiments that explicitly study the CS-UR relation might lead to new insights into basic behavioral and neurobiological processes that could translate into effective drug abuse intervention strategies.

Research has begun to elucidate some of the potential neurobiological processes mediating expression of this nicotine-conditioned association. For example, Schroeder et al. (2001) reported that rats that had an environment repeatedly paired with nicotine displayed a differential increase relative to controls in Fos expression in the shell of the 
nucleus accumbens, suggesting that cellular activity in this area is in response to the cues alone. Fos expression was also increased in areas such as the infralimbic, prelimbic, and anterior cingulate cortex. Furthermore, using microdialysis, Reid et al. (1996) and Reid, Ho, and Berger (1998) concluded that the correlated increase in dopamine in the nucleus accumbens of rats that had nicotine paired with the test environment was responsible for the enhanced (conditioned) locomotor effects of nicotine in this group. Indeed, systemic injection of the dopamine D1 receptor antagonist $\mathrm{SCH}-23390$ before a drug-free test blocked expression of nicotine-conditioned hyperactivity (Bevins et al., 2001). The dopamine D2/D3 antagonist eticlopride did not block expression of nicotine locomotor conditioning (Bevins et al., 2001). However, pretreatment with the more specific dopamine D3 antagonist SB-277011-A, or the D3 partial receptor agonist BP 897, blocked conditioned hyperactivity evoked by the context CS (Le Foll et al., 2003). These findings, combined with the increase in D3 mRNA expression in the shell of the nucleus accumbens in nicotine-paired rats, led Le Foll et al. (2003) to conclude that overexpression of D3 receptors is involved in the conditioned effects of nicotine.

In brief, these results suggest that the mesocorticolimbic system likely mediates, at least in part, expression of the conditioned association between environmental cues and the psychomotor effects of nicotine. However, much more research that directly manipulates this system is needed. For example, would a D3 antagonist bilaterally infused into the nucleus accumbens shell prevent expression of nicotine locomotor conditioning? Where in the brain would nicotine need to be microinfused to produce conditioning? Also, very little research has examined what CNS processes are involved in acquisition of the conditioned associations (cf. Palmatier \& Bevins, 2002). Regardless, pharmacotherapies that could selectively target this system might decrease cue-elicited CRs that lead to drug seeking and relapse. For example, bupropion hydrochloride, marketed as the smoking cessation drug Zyban, is effective at increasing smoking cessation rates (e.g., Hays \& Ebbert, 2003; Swan et al., 2003). Correlational and preclinical research has linked bupropion's clinical efficacy to its effects on purported reward and/or incentive-salience processes mediated by the mesolimbic system (Cryan, Bruijnzeel, Skjei, \& Markou, 2003; Learned-Coughlin et al., 2003; Li, Perry, \& Wong, 2002).

Although good initial progress has been made into understanding the neurobiological processes underlying nicotine-conditioned associations, much less is known about the importance of behavioral (environmental) variables on the development of these learned associations with nicotine. We recently finished a series of experiments inves- tigating the importance of the injection to placement in experimental apparatus interval in the acquisition of nicotine-conditioned hyperactivity (Bevins, Eurek, \& Besheer, in press). In the lingo of Pavlovian conditioning research, the time between the presentation of the CS (context) and the US (nicotine effects) is termed the interstimulus interval, or ISI. As the ISI is varied, conditioned responding tends to vary in an inverted-U function (Bevins \& Ayres, 1995; Pavlov, 1927; Smith, Coleman, \& Gormezano, 1969). A negative ISI (US onset before CS onset) tends to produce little or no CR; as the ISI increases, so does conditioned responding. At longer ISI values, conditioning tends to weaken. We found that nicotine-conditioned hyperactivity similarly varied with the ISI. There was relatively weak conditioning with a -15 -minute ISI (i.e., 0.4 $\mathrm{mg} / \mathrm{kg}$ nicotine injected 15 minutes before placement in the context CS for 30 minutes). Conditioning was robust if nicotine was injected immediately before placement (standard protocol). However, if nicotine was administered 15 minutes after placement or immediately after removal from the chamber (30-minute ISI), then there was no evidence for nicotine-conditioned hyperactivity. The inverted-U function in the nicotine locomotor conditioning task is consistent with a large body of Pavlovian conditioning research (e.g., Bevins \& Ayres, 1995; Cunningham, Okorn, \& Howard, 1997; Pavlov, 1927; Smith et al., 1969) and suggests that the temporal relation between the context CS and the psychomotor effects of the nicotine US is important for the development of a conditioned association.

In another experiment, we asked whether conditioning in one environment would affect the subsequent unconditioned and conditioned locomotor effects of nicotine in a second environment. In Phase 1, we used our standard conditioning protocol with a paired and unpaired group. In brief, one set of rats $(n=22)$ received nicotine $(0.4 \mathrm{mg} / \mathrm{kg})$ paired with Context 1 (i.e., black square chamber with rod floor) on 16 separate occasions. For these paired rats, nicotine was injected SC immediately before placement in Context 1 for 30 minutes. An unpaired control group $(n=11)$ received equal exposure to Context 1 and nicotine, except nicotine was administered in the home cage at least 2 hours after context exposure. Figure 2A shows the activity for each group across the 16 trials. As seen previously in our laboratory (e.g., Bevins et al., 2001) and others (Clarke \& Kumar 1983; Dwoskin et al., 1999; Stolerman, Fink, \& Jarvik, 1973), acute nicotine had a locomotor-suppressant effect that was replaced by locomotor activation with repeated exposure to nicotine.

In Phase 2, the paired rats were divided into two groups ( $n=11$ /group) with the restriction that activity in Phase 1 did not differ statistically. Rats in one group, $\mathrm{P}: \mathrm{C} 1 \rightarrow \mathrm{C} 2$, 

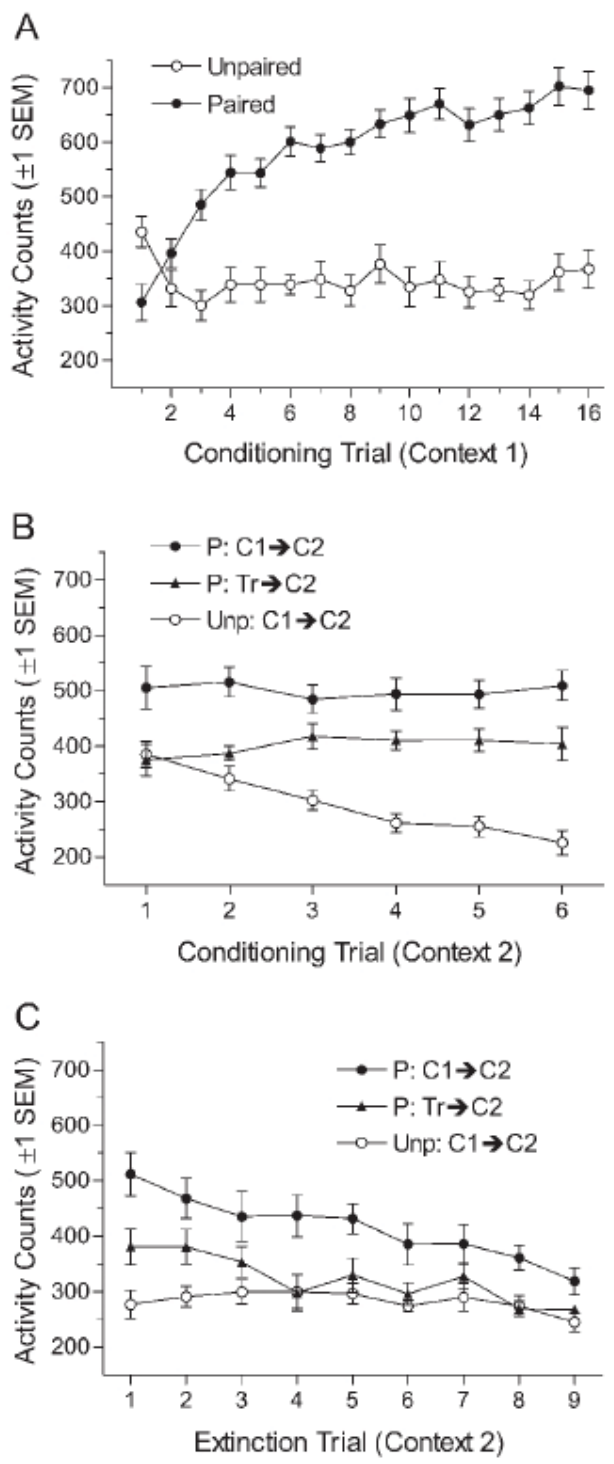

Figure 2: Mean Activity Levels forTransfer of Excitation Experiment

NOTE: (A) Mean activity levels for Phase 1 conditioning of Context $1(\mathrm{C} 1)$ for paired $(\mathrm{P})$ and unpaired $(\mathrm{U})$ rats. (B) Mean activity levels in Context 2 (C2) for each group in Phase 2 (Tr in group name $=$ transport cart). There was a main effect of group, $F(2,30)=$ $26.84, p<.001$; a main effect of conditioning trial, $F(5,150)=3.52$, $p=.005$; and a significant Trial $\times$ Group interaction, $F(10,150)=$ $6.43, p<.001$. Subsequent least squares difference (LSD) comparisons indicated that $\mathrm{P}: \mathrm{C} 1 \rightarrow \mathrm{C} 2$ was, in general, more active than the other two groups and that $\mathrm{P}: \operatorname{Tr} \rightarrow \mathrm{C} 2$ was more active than unpaired controls, $p s \leq .001$. (C) Activity for each group across Context 2 extinction trials (Phase 3$)$. There was a main effect of group, $F(2$, $30)=8.45, p=.001$; a main effect of conditioning trial, $F(8,240)$ $=15.92, p<.00$; and a significant Trial $\times$ Group interaction, $F(16$, $240)=3.11, p<.001$; Subsequent LSD comparisons indicated that $\mathrm{P}: \mathrm{C} 1 \rightarrow \mathrm{C} 2$ was, in general, more active than the other two groups, $p s \leq .009$, but that overall activity did not differ between $\mathrm{P}: \mathrm{Tr} \rightarrow \mathrm{C} 2$ and the unpaired control, $p=.239$. were placed in Context 1 for 10 minutes then removed and injected with nicotine $(0.4 \mathrm{mg} / \mathrm{kg})$ immediately before placement in Context 2 (white circular chambers described earlier) for 30 minutes. This protocol was repeated daily for 6 days. The other paired group, $\mathrm{P}: \operatorname{Tr} \rightarrow \mathrm{C} 2$, were handled similarly but were placed back into the transport cart $^{1}$ for 10 minutes before being removed, injected with nicotine, and placed in Context 2 for 30 minutes. Thus, the only difference between the groups was whether the previously conditioned context (Context 1 ) preceded nicotine exposure and subsequent conditioning in the second environment (Context 2). Unpaired rats, Unp:C1 $\rightarrow$ $\mathrm{C} 2$, were treated like group $\mathrm{P}: \mathrm{C} 1 \rightarrow \mathrm{C} 2$ except saline was administered before placement in Context 2 and nicotine was given in the home cage at least 2 hours after the conditioning trial. Figure 2B shows the activity in Context 2 for all groups. Interestingly, brief exposure to a previously conditioned environment (Context 1) enhanced the locomotor stimulant effects of nicotine. That is, nicotine-induced activity was greater in group $\mathrm{P}: \mathrm{C} 1 \rightarrow \mathrm{C} 2$ than in $\mathrm{P}$ : $\mathrm{Tr} \rightarrow \mathrm{C} 2$.

Phase 3 was extinction of Context 2 for all groups. Each rat was injected with saline once daily for 9 days (no US) and placed in Context 2 for 30 minutes. Relative to the unpaired control, both paired groups appeared to display some conditioned hyperactivity on the first extinction trial (see Figure 2C). This conditioned hyperactivity, however, was enhanced for group $\mathrm{P}: \mathrm{C} 1 \rightarrow \mathrm{C} 2$ and persisted for more extinction trials than that of group $\mathrm{P}: \operatorname{Tr} \rightarrow \mathrm{C} 2$. This data pattern is interesting because it indicates that enhancement of locomotor stimulant effects of nicotine in Phase 2 resulted in a more robust conditioned response that was more resistant to extinction. Whether the enhancement reflects second-order conditioning, generalization of excitation, and so on will have to await further research. Regardless, this result is consistent with the earlier suggestion that research focusing on the relations between the $\mathrm{CS}$ and the nature of the unconditioned response might provide important insights into factors mediating drug conditioning.

Clearly, more basic research on associative learning processes with nicotine as the US is required. At the neurobiological level, the substrates mediating drug conditioning have only begun to be investigated. This work has primarily focused on mesocorticolimbic and dopaminergic processes. Other receptor systems such as glutamatergic or GABAergic would be of interest (cf. Bevins et al., 2001; Schroeder et al., 2001), as well as brain structures outside the mesocorticolimbic system (e.g., hippocampus, reticular formation). In addition, it seems important to extend the generality of these results to other rat strains-only Wistar and Sprague Dawley rats have been used-and to mice. This latter extension would provide the opportunity to study contributing fac- 
tors at the genetic level. Finally, more basic research at the behavioral level is required. Although the list of questions at this level is long, one especially important question is whether an extinguished conditioned response (cf. Figure 2C) will show renewal, reinstatement, or spontaneous recovery. For example, would exposure to a general stressor result in a return (reinstatement) of extinguished conditioned hyperactivity? These phenomena are taken as evidence that extinction is an alternative learning history that competes with old learning (Bouton, 1991; Pavlov, 1927) and suggest a potential cause of relapse to old patterns of drug seeking and taking (cf. Bouton, 2002). If so, then the nicotine locomotor conditioning model could be used to better understand factors that induce relapse, as well as potential interventions that might decrease chances of relapse.

\section{EXTENDING ASSOCIATIVE THEORY: NICOTINE AS A CS}

Most of the research on associative learning with nicotine has conceptualized nicotine as the US. However, recent research from our laboratory with nicotine (Besheer, Palmatier, Metschke, \& Bevins, 2004; Palmatier, Peterson, Wilkinson, \& Bevins, 2004; Sanderson et al., 2003) and other laboratories with ethanol, morphine, diazepam, or pentobarbital (Alessi, Roll, Reilly, \& Johanson, 2002; Greeley, Lê, Poulos, \& Cappell, 1984; Kim, Siegel, \& Patenall, 1999; Revusky, Davey, \& Zagorski, 1989) suggest that this focused conceptualization of nicotine might not completely capture the complexity of the associative processes involving nicotine and, by theoretical extension, the associative factors contributing to tobacco dependence. We suggest that a more complete associative analysis of nicotine dependence will also include nicotine in the role of a CS. As a CS, nicotine should acquire new or additional affective properties by virtue of being reliably paired with other appetitive stimuli (e.g., food, drink, work breaks, positive self-image, peergroup inclusion, etc.).

One obvious prerequisite of this theoretical extension is that nicotine must have perceptible stimulus effects. Indeed, there is a substantial operant drug discrimination literature showing that the pharmacological (interoceptive) effects of nicotine can guide reinforced responding in human and nonhuman animals. For example, rats can learn to turn consistently to one of two arms of a T-maze that contains food reward depending on whether nicotine (0.4 $\mathrm{mg} / \mathrm{kg}$, base) or saline was administered systemically (e.g., Schechter \& Rosecrans, 1972). In this discrete-trial situation, nicotine is referred to as a discriminative stimulus (SD). Methodologically, the nicotine SD sets the occasion on which a response (e.g., left turn) will be reinforced. The opposite response-outcome relation is cued by administration of saline (i.e., no nicotine). A more popular variant of this task in behavioral pharmacology laboratories has the pharmacological effects of nicotine $(0.4 \mathrm{mg} / \mathrm{kg}$, base $)$ serving as a cue for responding on one of two levers in an operant conditioning chamber. In this task, if the rat is pretreated with nicotine, then responding 10 consecutive times on the right lever is reinforced with food; when pretreated with saline, left lever responding is reinforced (e.g., Stolerman, 1989).

Reinforced behavior in humans can also come under the control of the SD effects of nicotine. For example, in a study by Perkins, DiMarco, Grobe, Scierka, and Stiller (1994), controlled doses of nicotine were delivered to humans in nasal spray. Participants readily learned to place 10 poker chips in a "nicotine pile" if the nasal spray contained nicotine. If the spray contained only vehicle (no drug), the participants learned to place the chips in a "vehicle pile." Notably, control of chip placement in these participants was sensitive to nicotine dose. After acquisition of the discrimination, the less nicotine administered in the nasal spray, the more chips participants moved from the nicotine to the vehicle pile. The operant drug discrimination research clearly indicates that a drug state such as the one induced by the pharmacological effects of nicotine can serve as an interoceptive cue for the presence of a response-outcome relation. More important, drugdrug conditioning research indicates that the pharmacological effects of a drug can serve as a CS for the pharmacological effects of another drug. For example, Revusky et al. (1989) paired pentobarbital $(32 \mathrm{mg} / \mathrm{kg})$ repeatedly with amphetamine $(24 \mathrm{mg} / \mathrm{kg})$ in rats. Pentobarbital, the putative CS, was administered 30 minutes before amphetamine, the putative US. Relative to controls that received similar exposure to the drugs in an unpaired fashion, the pentobarbital CS came to evoke an increase in heart rate. Acquisition of the heart rate CR was sensitive to CS salience and the nature of the US, and once acquired, the CR survived a 43-day retention interval (Reilly \& Revusky, 1992; Revusky et al., 1989; Revusky \& Reilly, 1990). An interesting variant of this drug-drug conditioning protocol uses a low dose of a drug as a CS for a later and typically larger effect of the same drug (US). For instance, Greeley et al. (1984) repeatedly followed a low dose of ethanol $(0.8 \mathrm{~g} / \mathrm{kg})$ with a higher dose of ethanol $(2.5 \mathrm{~g} / \mathrm{kg})$. The low dose of ethanol acquired the ability to evoke an increase in body temperature. The authors suggested that the low dose of ethanol served as a CS eliciting a compensatory hyperthermic CR for the high dose of ethanol (US) that produces a hypothermic UR. More recently, Siegel and colleagues have investigated the ability of the early pharmacological effects 
of morphine to serve as a CS for its later, more profound analgesic effects in rats (e.g., Kim et al., 1999; Sokolowska, Siegel, \& Kim, 2002; see also McDonald \& Siegel, 2004).

Recent research from our laboratory has extended these findings on drugs as conditional stimuli to nicotine and to a nondrug US (Besheer et al., 2004). In that research, rats were given intermixed saline and nicotine sessions. On nicotine sessions, rats were injected with nicotine $(0.4 \mathrm{mg} / \mathrm{kg}) 5$ minutes before placement in a standard operant chamber for 20 minutes. In that 20 -minute session, the rats had intermittent access to a 4-second dipper cup of sucrose solution (eight per session). Saline sessions were similar, except saline was administered and sucrose was not delivered. Rats tend to search in a location where appetitive outcomes have reliably occurred in the past (i.e., goal tracking; Boakes, 1977; Farwell \& Ayres, 1979). Thus, our main measure in nicotine sessions was the rate of dipper entries (goal tracking) before the first sucrose delivery; a comparable rate was calculated for saline session. Rats readily learned this Pavlovian discrimination as evidenced by more goal tracking during the nicotine session than in the saline sessions. Consistent with a Pavlovian conditioning account, this goal-tracking $\mathrm{CR}$ was susceptible to extinction (Pavlov, 1927; Wasserman \& Miller, 1997). That is, repeated presentation of the nicotine cue without the sucrose US resulted in a decrease in conditioned responding across trials.

Associative learning theory also predicts that changes in features of the CS should produce a loss of conditioned responding. Indeed, nicotine-evoked goal tracking was dose dependent: As the dose (i.e., salience) of nicotine decreased, so did the goal-tracking CR. Furthermore, amphetamine $(1 \mathrm{mg} / \mathrm{kg})$ in a stimulus-substitution (generalization) test evoked, at best, a CR about $25 \%$ of that controlled by the nicotine cue (Besheer et al., 2004). This latter result has two important implications. First, the increase in goal tracking during the nicotine cue is not due to its psychomotor stimulant effects increasing dipper entry rates. If this were the mechanism, then amphetamine, a potent psychomotor stimulant at $1 \mathrm{mg} / \mathrm{kg}$ (cf. Palmatier et al., 2003), should have evoked a more complete CR (about 100\%). This did not occur. Second, the lack of substitution between nicotine and amphetamine suggests that rats learned more than a drug versus no drug, or a stimulant versus no stimulant, discrimination. Rather, the interoceptive CS controlling goal tracking includes pharmacological effects that are specific to nicotine. Notably, the interoceptive cueing effects appear to be mediated by CNS nicotinic acetylcholine receptors (nAChRs). That is, CR evoked by nicotine is prevented by pretreatment with the central and peripheral nAChR antagonist mecamylamine; pretreatment with the periph- eral $\mathrm{nAChR}$ antagonist hexamethonium had no effect on conditioned responding (Besheer et al., 2004). Combined, these results suggest that pharmacological effects of nicotine can enter into a conditioned association with an appetitive nondrug US. As a result of this association, nicotine comes to evoke a response that it did not previously control: goal tracking.

To date, all of the published research has used a 0.4 $\mathrm{mg} / \mathrm{kg}$ dose of nicotine as the CS. This is the most common dose used as an SD in operant drug discrimination research. However, some of the operant drug discrimination research has successfully used lower doses of nicotine as the SD (e.g., Hirschborn \& Rosecrans, 1974; Stolerman et al., 1984). A fading technique is one method used to train rats with a lower dose of nicotine. In that technique, rats are first trained to discriminate the $0.4 \mathrm{mg} / \mathrm{kg}$ nicotine dose from saline to guide reinforced responding. Once discrimination performance is stable, the dose of nicotine is decreased (e.g., from 0.4 to $0.2 \mathrm{mg} / \mathrm{kg}$ ). When performance restabilizes, the dose is lowered again (cf. Stolerman et al., 1984). In a set of 7 male Sprague Dawley rats, we sought to determine whether a lower dose of nicotine could function as a CS using this fading procedure. Accordingly, rats were trained in the Pavlovian discrimination procedure described earlier in which $0.4 \mathrm{mg} / \mathrm{kg}$ nicotine signaled intermittent access to the sucrose US; saline (no drug) signaled no sucrose. Similar to our previous research, rats acquired the discrimination as indicated by more goal tracking before sucrose was delivered in the nicotine session than in a comparable time in the saline session (see the leftmost bars in Figure 3A). When the nicotine CS was shifted from $0.4 \mathrm{mg} / \mathrm{kg}$ to $0.2 \mathrm{mg} / \mathrm{kg}$, 5 of the 7 rats displayed a disruption in discrimination performance as indicated by a negative difference score (see leftmost scatter plot in Figure 3B; figure caption describes difference score). With continued training, the $0.2 \mathrm{mg} /$ $\mathrm{kg}$ nicotine dose maintained differential conditioned responding (center bars, Figure 3B). The shift to a $0.1 \mathrm{mg} / \mathrm{kg}$ dose was not as disruptive as the previous dose shift: 2 of 7 rats displayed a negative difference score. As training continued, the $0.1 \mathrm{mg} / \mathrm{kg}$ dose of nicotine also served as the $\mathrm{CS}$, as indicated by differential control of the goal-tracking CR. Finally, when the dose of nicotine was lowered to $0.05 \mathrm{mg} / \mathrm{kg}, 6$ of the 7 rats displayed disruption in conditioned responding. Thus, similar to the operant drug discrimination research, a relatively low dose of systemically administered nicotine $(0.1 \mathrm{mg} / \mathrm{kg}, \mathrm{SC})$ can serve as a conditional stimulus.

This extension of associative learning theory to include drugs states as CSs that enter into associations with temporally contiguous appetitive (rewarding) events has the potential to contribute to our understanding of tobacco 
dependence and hence benefit intervention and prevention methods. For example, the transition from experimenting with cigarette smoking into a dependence phase might be facilitated if the pharmacological effects of nicotine signal appetitive events. In adolescents, the stimulus effects of
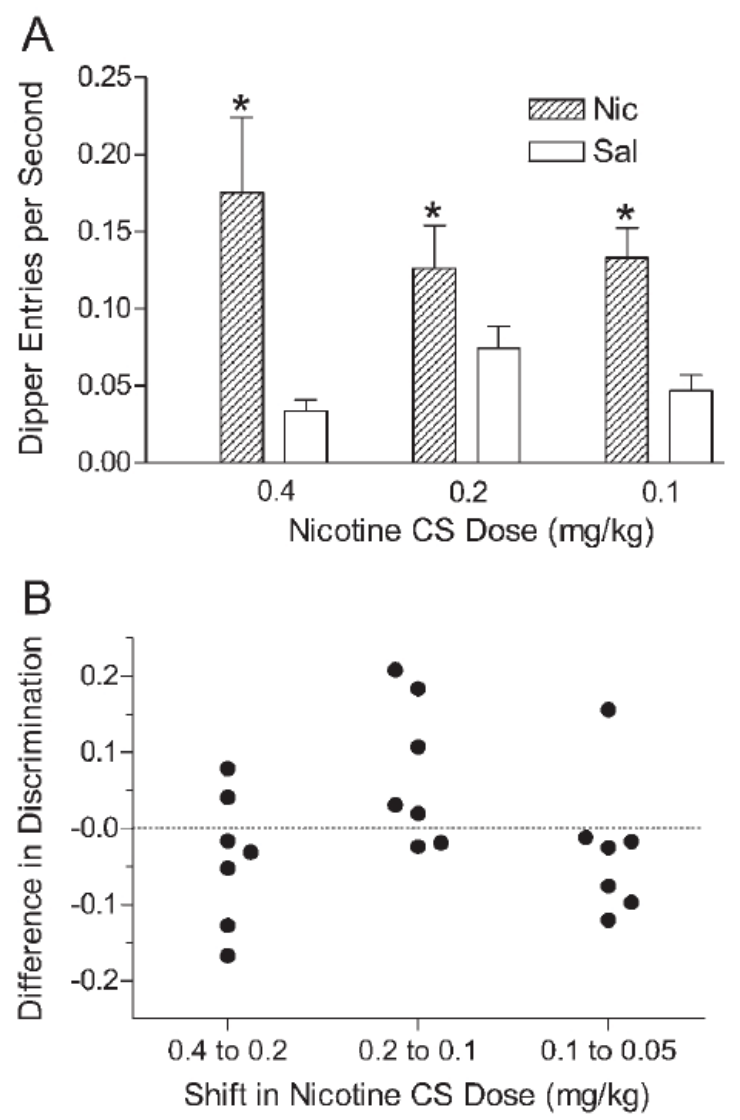

Figure 3: Results from Nicotine CS Fading Dose Experiment

NOTE: (A) Mean dipper entries per second for the final nicotine and saline training session before each dose shift. Dipper entries on nicotine sessions were from the early portion of the session before any sucrose was delivered; a similar time period was used for saline sessions. Relative to saline values, there were significantly more dipper entries at each nicotine dose, $t s(6) \geq 2.92$, $p s \leq .027$, indicating differential control of a goal-tracking conditioned response by the nicotine conditional stimulus (CS). (B) Individual data at each dose shift. The difference in discrimination measure for each rat was calculated by taking the difference between dipper entry rate for nicotine and saline on the last training session of the maintenance dose (e.g., $0.4 \mathrm{mg} / \mathrm{kg}$ ) and subtracting that value from the difference between dipper entry rate for nicotine and saline on the first training session for the new nicotine dose (e.g., $0.2 \mathrm{mg}$ / $\mathrm{kg}$ ). Thus, a negative value indicates that the discrimination was disrupted by the shift in nicotine dose (i.e., the difference between nicotine and saline performance was less under the new training dose). low nicotine doses can be adventitiously paired with other rewarding outcomes such as acceptance into a peer group, positive self-images, and/or alcohol consumption. A similar suggestion for methamphetamine and caffeine abuse was made by Alessi et al. (2002). That suggestion was based on their finding with human participants that had a nonpreferred drug (typically diazepam) paired with increased pay during a subsequent computer task. The monetary outcome (US) induced a preference for interoceptive effects of diazepam (CS). Or, in the words of the authors, "drug (diazepam) may have acquired the properties of a conditioned reinforcer as a result of its association with money" (p. 81, emphasis added). Although this analysis is speculative given our current state of knowledge, we would extend it to suggest that an appetitive associative learning history would also make quitting more difficult and relapse into chronic pattern of smoking more likely if reexposed to nicotine after abstinence. From this perspective, the pharmacological effects of the low doses of nicotine from the initial inhalations of the first cigarette after a period of abstinence would not only have the primary reinforcing effects, but it would also include these acquired appetitive associations and their impact on incentive-salience processes. In addition to this conditioned reward, appetitive CRs tend to be search or approach-like behaviors to stimuli or situations in which the US had occurred in the past (e.g., Timberlake \& Lucas, 1989; Panksepp et al., 2004). Such conditioned responding would likely increase the chances an individual will seek contexts that encourage further smoking.

\section{FURTHER EXTENSIONS: NICOTINE AS A MODULATOR}

In addition to the potential role of nicotine as a CS, recent research indicates that nicotine can modulate associative processes in a conditional and unconditional manner. In the conditional sense, the interoceptive cueing effects of nicotine can serve as a contextual stimulus that sets the occasion for an association between a discrete exteroceptive CS (e.g., light cue) and a rewarding US (Palmatier et al., 2004; Sanderson et al., 2003). Thus, the CS-US association is said to be conditional on the drug state (context). In the unconditional sense, nicotine appears to amplify the salience of other stimuli that have some incentive value (e.g., Caggiula et al., 2001; Olausson, Jentsch, \& Taylor, 2004a). This amplification has been described as unconditional in that the effects of nicotine do not depend on any contingency between nicotine administration and the incentive stimulus (Caggiula et al., 2002; Donny et al., 2003; Olausson et al., 2004a). Both classes of modulation by nicotine, "occasion setting" and "incentive amplification," likely have important implications for the treatment and prevention of tobacco use and will thus be discussed in more detail in the remainder of this review. 


\section{Occasion Setting}

If nicotine can function as a discriminative stimulus that occasions a response-outcome (reinforcer) relation and can function as a CS that enters into direct association with a nondrug US, then nicotine should serve to occasion the presence of CS-US contingency that does not necessarily exist outside of that drug state. Given the importance that theories of drug abuse place on associative learning processes, surprisingly little research has been conducted on the ability of drug states to occasion a Pavlovian association. Most of what we know about drugs as occasion setters comes from the area of discriminated taste aversion in which the pharmacological effects of a drug occasion (signal) an aversive CS-US association (e.g., Revusky, Coombes, \& Pohl, 1982; Skinner, Goddard, \& Holland, 1998). Take as an example the following experiment by Martin, Gans, and van der Kooy (1990). In this research, water-deprived rats were given limited access to a $0.1 \%$ saccharin solution (i.e., CS). This saccharin CS was paired with lithium chloride-induced illness (i.e., US) only when the presession in-

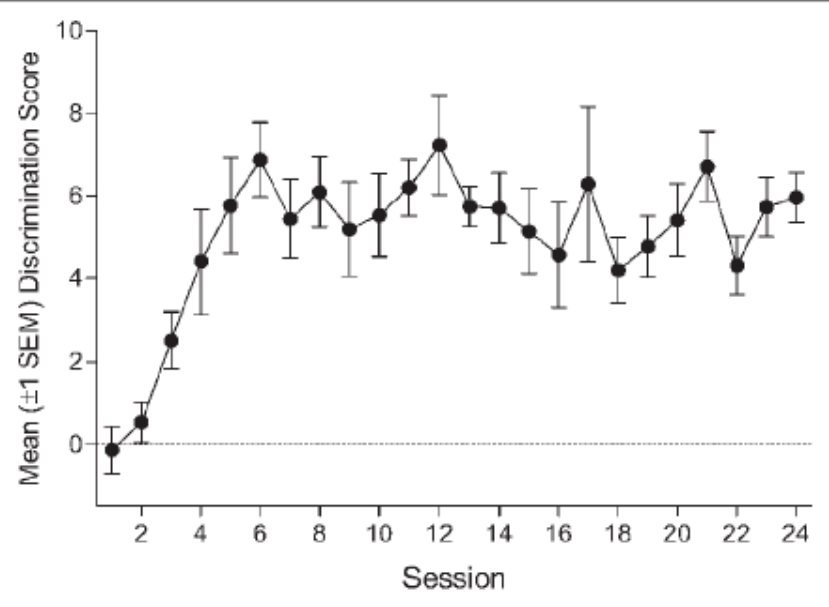

Figure 4: Acquisition of a Discrimination for Nicotine as an Occasion Setter for an Appetitive CS-US Association.

NOTE: The light CS was followed by 4 -second access to $26 \%$ sucrose in the nicotine state; no programmed consequence followed the light CS in the saline state. Dipper entry data were first converted to elevation scores using the following formula: the number of dipper entries occurring during the 15 seconds immediately before the CS (i.e., pre-CS) minus the number of dipper entries during the light CS. The mean elevation score on each saline session for a rat was then subtracted from the corresponding nicotine elevation score to determine the discrimination score. Positive values indicate more dipper entries during the $\mathrm{CS}$ on nicotine sessions relative to saline sessions. Data in the graph were previously published in a different form (Palmatier et al., 2004). jection was morphine; no illness followed saccharin consumption if the presession injection was saline. Morphine acquired modulatory control over the saccharin CS-lithium chloride US association as evidenced by less saccharin intake on morphine trials than on saline trials. To our knowledge, there is no published demonstration that nicotine can serve as an occasion setter in this discriminated taste aversion procedure. Perhaps this deficit is due to the aversive effects of nicotine. Novel tastes paired with doses of nicotine commonly used in operant drug discrimination evoke conditioned aversive taste reactions and avoidance responses in rats (Parker, 1995). Such responses are not typically seen with drugs such as morphine, amphetamine, or cocaine.

Although characterizing the stimulus properties of nicotine in the discriminated taste aversion paradigm could be very interesting, our research and theoretical framework was more focused on appetitive processes within the incentivemotivational systems (cf. Robinson \& Berridge, 1993; Wise, 2004; see earlier discussion). Therefore, a more natural question for us to ask was whether nicotine could modulate the appetitive conditional value of a discrete environmental cue. Answering this question required a slight modification of the previously described research in which nicotine served as a CS. Rather than nicotine directly signaling intermittent access to the sucrose US, in these modulatory studies, a discrete 15 -second cue (e.g., light) signaled the delivery of sucrose in the nicotine state $(0.4 \mathrm{mg} / \mathrm{kg}, \mathrm{SC})$. The same light cue was presented in the saline state, but sucrose was not delivered. Thus, nicotine disambiguates the meaning of the light. All other training parameters were identical to the nicotine CS research described earlier (see also Palmatier et al., 2004).

As indicated by an increasingly positive within-subject discrimination score in Figure 4, rats $(n=7)$ readily learned the discrimination with more goal tracking during the light CS on nicotine sessions than in saline sessions. Notably, conditioned responding stabilized quickly (fewer than 20 sessions; 10 nicotine and 10 saline sessions). Subsequent experiments have explored various associative and pharmacological aspects of nicotine as a contextual modulator. For example, this modulatory function appears to be mediated by central nAChRs. Pretreatment with mecamylamine blocked cue-evoked goal tracking in the nicotine state, whereas pretreatment with hexamethonium had no effect (Palmatier et al., 2004). This modulatory effect, similar to the CS effect, was sensitive to shifts in salience (i.e., dose) and time between injection and placement (Palmatier et al., 2004, in press). More important, after rats have acquired the discrimination, repeated administration of nicotine without presentations of the light or sucrose (i.e., extinction) does not disrupt the goal-tracking $\mathrm{CR}$ when the light $\mathrm{CS}$ was reintroduced. This insensitivity to extinction of the nicotine modulator suggests that nicotine-specific goal tracking in this 
drug-modulation task likely reflects a higher order association with the light CS-sucrose US rather than expression of a weak nicotine-sucrose association (Palmatier, 2004; Palmatier et al., 2004).

From an addiction treatment perspective, perhaps the most important finding to date is that functionally similar but pharmacologically distinct drug states substitute for one another in a transfer test. For example, chlordiazepoxide (CDP) does not prompt conditioned responding if rats were trained with nicotine as the modulator. Conversely, nicotine does not evoke a $\mathrm{CR}$ if rats were trained with $\mathrm{CDP}$ as the modulator. Thus, nicotine and CDP are pharmacologically distinct in these substitution tests, that is, no stimulus generalization (i.e., Palmatier et al., 2004, in press). However, when rats were trained such that nicotine was a modulator for one CS (e.g., white noise), CDP was a modulator for another CS (e.g., light), and saline signaled that neither discrete CS would be followed by sucrose the substitution (transfer) pattern was very different. That is, each drug state transferred conditional control over goal tracking to the other discrete cue. In this example, nicotine now prompted conditioned responding to the light CS even though nicotine and CDP are pharmacologically distinct and the light CS had never been paired with sucrose in the presence of nicotine. More important, a novel drug state (amphetamine) did not control conditional responding to either CS, indicating that training two discriminations within a rat did not result in a drug-no drug discrimination (Palmatier, 2004). These studies suggest that the conditional control exerted by nicotine is analogous to Pavlovian occasion setting demonstrated with exteroceptive contexts and discrete cues (cf. Holland, 1999; Swartzentruber, 1998). Drug states that do not share stimulus properties become functionally equivalent when they are trained in a similar manner. This finding could have important implications for nicotine addiction and the development of behavioral therapies because generalization is based on commonality of higher order associative processes. Although we will delay further discussion of this point until the concluding comments, we should note that despite some evidence to the contrary (M. A. Miller, Parker, Keely, Johnson, \& Schaal, 2002), we were not surprised to find transfer of conditional control by drug contexts. Indeed, recent associative learning theories place tremendous emphasis on the modulatory influence of discrete and contextual cues in Pavlovian conditioning (e.g., Bouton, 1993, 2002; Kasprow, Schachtman, \& Miller, 1987; Rescorla, 1986; Schmajuk, Lamoureux, \& Holland, 1998). However, very few preclinical models have examined these potential modulatory processes in relation to drug abuse (cf. Crombag \& Shaham, 2002). Thus, there remains a critical need to bridge current theoretical models of associative learning and preclinical models of drug abuse.

\section{Incentive Amplification}

As noted earlier, recent research has shown that nicotine amplifies the salience of other stimuli that have some incentive value. For example, Olausson, Jentsch, and Taylor (2003) preexposed rats to nicotine or saline for 15 days. After this exposure, all rats received pairings of a 5 -second light + tone compound CS with 5-second access to water (i.e., the US). Across training sessions, rats that received preexposure to nicotine acquired a goal-tracking $\mathrm{CR}$ more readily than did rats that were never preexposed to nicotine. In addition, acute and chronic nicotine exposure enhances the ability of an appetitive CS to promote a novel lever-pressing response in rats (i.e., enhanced conditioned reinforcement; Olausson et al., 2004a, 2004b).

Although Olausson and colleagues have focused on nicotine's ability to amplify the effects of conditional incentive stimuli, Caggiula and colleagues (e.g., Caggiula et al., 2001; Donny et al., 2003) have focused on the ability of nicotine to enhance the incentive value of unconditioned reinforcers. For example, bar pressing in rats can be maintained by contingent presentation of a 1-second cue light-on, 1-minute house light-off visual stimulus. Notably, responding for this visual stimulus increases when nicotine is infused intravenously in the same session (Donny et al., 2003). This shift in responding does not depend on a contingency between nicotine and the stimulus. That is, nicotine enhanced responding for the visual stimulus when it was accompanied by contingent nicotine infusions or nicotine infusions delivered in a response-independent manner (i.e., yoked or continuous infusions).

The discovery that nicotine amplifies the incentive salience of conditional and unconditional stimuli is exciting and has prompted many new questions about the nature of this interaction. For instance, does nicotine enhance responding for conditioned reinforcers because it increases the incentive value of the US or does it simply strengthen the associative links between the CS and US? Or, could nicotine alter the incentive value of any cue that was controlled by operation of a manipulandum? Currently, such changes appear to be US dependent, but additional experiments are needed to distinguish between these possibilities. For example, a replication of the research by Olausson and colleagues (2004a, 2004b) that included assessment of the effects of nicotine on responding for familiar stimuli not previously paired with a reward (i.e., unpaired group) is needed. Perhaps nicotine would enhance responding for any stimulus that was delivered under an operant contingency. Future studies should begin to determine whether nicotine enhances the value of any stimulus that an organism encounters, or whether these effects of nicotine are limited to stimuli that already possess some conditional or 
unconditional incentive-motivational value. In addition, are the neurobiological processes mediating this effect similar or distinct from those suggested in Robinson and Berridge's incentive-sensitization theory of addiction (Berridge \& Robinson, 2003; Robinson \& Berridge, 1993)?

\section{SUMMARY AND CONCLUDING THOUGHTS}

The more comprehensive role of associative learning processes involving nicotine described in this review might provide answers to some puzzling questions about nicotine dependence. For example, in a recent and thought-provoking review, Caggiula and colleagues (2001) highlighted the apparent paradox between the subtle psychoactive effects of nicotine and its potent abuse liability. They argued that nicotine-paired stimuli were at least as important as the reinforcing effects of nicotine in maintaining self-administration. We concur, and the research supports such a proposition and points to additional processes that likely contribute to the tenacity of the smoking habit. Figure 5 summarizes these processes. First, nicotine is a potent US that enters into associations with stimuli that are contiguous with its CNS effects (connection 1 in Figure 5). These pairings of nicotine with environmental events (e.g., lighter, throat irritation) imbues those events (CSs) with incentive salience and hence the ability to evoke craving, drug "wanting," and approach (Berridge \& Robinson, 2003; Robinson \& Berridge, 1993). More important, these associations tend to be specific to or occasioned by situational cues (e.g., bar or pub, smoking area, home, vehicle, etc.), making simple extinction in a clinical setting less than optimal from an associative learning perspective (cf. Bouton, 2002; see also connection 3 in Figure 5 and later discussion).

The stimulus properties of nicotine can function as a $\mathrm{CS}$ and enter into association with other appetitive stimuli (Besheer et al., 2004; see connection 2 in Figure 5). Thus, nicotine acquires additional incentive properties related to the USs (e.g., alcohol, peer acceptance). The appetitive CRs evoked by the nicotine CS will likely be search or approachlike behaviors to stimuli or situations in which the US had occurred in the past. Many of these situations will encourage further smoking. Recall that nicotine has the ability to amplify incentive salience of conditioned and unconditioned reinforcers (rewards). The research by Caggiula and colleagues showing that nicotine unconditionally enhances the incentive salience of a mildly rewarding visual stimulus (e.g., Donny et al., 2003) suggests that nicotine might enhance the appetitive/incentive effects of potential USs that are paired with the nicotine CS (solid arrow "a" in Figure 5). If so, this incentive-amplifying effect of nicotine might facilitate its ability to serve as a CS for a rewarding outcome. Arguably, any conditioned appetitive value that nicotine acquired as a CS could be enhanced by its own incentive-amplifying effect on these USs. In other words, the magnitude of the US (e.g., alcohol, peer acceptance) is enhanced by the incentive-amplifying effects of nicotine. Albeit speculative, from the perspective of the present review, this might mean that US enhancement by nicotine will increase the rate at which it serves as a CS and that the strength of the conditioned association will be stronger than typically mediated by that US in the absence of nicotine (dashed arrow "a" in Figure 5).

It is important to note that even in the absence of this incentive-feedback loop, the finding that nicotine serves as a $\mathrm{CS}$ and acquires additional appetitive/incentive value might serve to enhance its ability to function as a US (Connection 1 ), thus enhancing the environment CS-nicotine US associations (dashed arrow " $\mathrm{b}$ "”). In addition, Olausson and colleagues' (2004a, 2004b) research indicates that nicotine can amplify the incentive salience of conditioned reinforcers. As environmental cues enter into conditioned associations with nicotine, they presumably acquire conditioned appetitive/ rewarding value. An interesting possibility is that the incentive-amplifying effects of nicotine might act on these CSs (solid arrow "b"). If acquired incentive salience increases the "attention-grabbing" ability of the CS (cf. Robinson \& Berridge, 1993), then enhancement of this CS quality by nicotine might increase the strength of the conditioned association (dashed arrow " $c$ "). These incentive-amplifying effects could also enhance conditioned associations for which nicotine serves as an occasion setter (dashed arrow "d"”; see the following paragraph). Additional research will be required to examine the validity of these incentive-feedback functions (dashed lines) and their potential contribution to the difficulty that many long-term smokers have quitting.

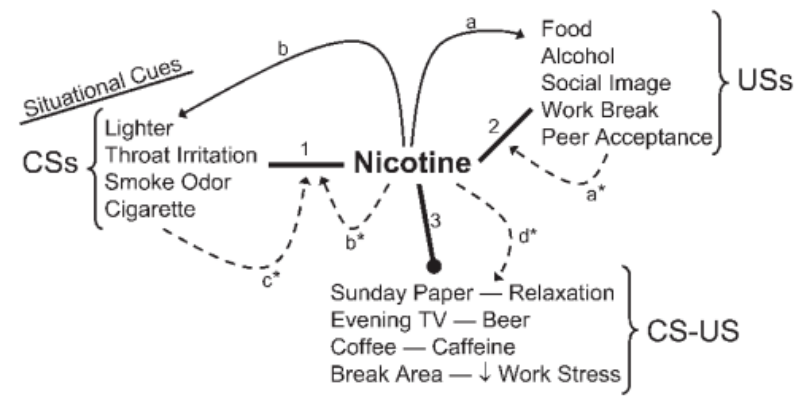

Figure 5: Extensions of Associative Learning Theory to Nicotine Addiction Discussed in the Review

NOTE: The main text describes the graphic in detail. In brief, connections 1,2, and 3 reflect nicotine in the role of the unconditioned stimulus (US), conditional stimulus (CS), and occasion setter, respectively. Solid arrows "a" and "b" refer to nicotine's ability to amplify incentive salience. The dashed arrows (" $a$ *" to " $d$ ") denote potentially interesting feedback functions in which conditioned associations may be strengthened. 
Finally, the extensions of associative learning theory to tobacco abuse proposed in this review demand that we consider the importance of conditional modulatory cues (occasion setters) whether they are the pharmacological effects of nicotine (see connection 3 in Figure 5) or other situational (context) cues. Clinically, if some situational cues are associated with the reinforcing/psychoactive effects of nicotine, and the meaning of these cues can be modulated by other stimuli, then an associative learning-based approach to smoking cessation requires an individual to identify and extinguish not only smoking cues (CS) but also the modulators that instantiate their ability to predict smoking outcomes. Extinction of a modulator is more complicated than extinction of a CS and requires that the modulator now signal that the cue will be nonreinforced (R. R. Miller \& Oberling, 1998). In our preclinical model, the discrete CS (e.g., light) would not be followed by sucrose in the presence of nicotine. However, the same CS would be followed by sucrose in the presence of saline (no drug). Preliminary research in our laboratory indicates that this type of training can eliminate the modulatory control of nicotine. This proposed framework will also help identify stimulus classes that are more or less likely to modulate the meaning of smoking cues. For example, human research suggests that there is a special relation between drinking alcohol and smoking cigarettes. On average, $85 \%$ to $90 \%$ of alcoholics in treatment are habitual smokers, in contrast to a $20 \%$ to $25 \%$ smoking rate in the general population (e.g., Harris, 1980; Hughes, 1995). Alcohol consumption increases smoking rates in chronic smokers (Shiffman et al., 1994) and increases the likelihood of relapse in abstinent smokers (Brandon, Tiffany, Obremski, \& Baker, 1990; Shiffman, 1986). Interestingly, chronic smokers report greater urges to smoke and show more potent reactivity to smoking cues when they are under the influence of alcohol (Burton \& Tiffany, 1997; Sayette, 2002).

To date, the bulk of research into this ethanol/nicotine interaction has explored genetic (e.g., de Fiebre, Dawson, \& de Fiebre, 2002) or neurobiological factors (e.g., Larsson \& Engel, 2004; Owens et al., 2003). A few investigators have suggested a role for learning histories in this interaction (Burton \& Tiffany, 1997; Sayette, 2002). For example, the interoceptive effects of ethanol might serve as a CS for smoking (Sayette, 2002). We suggest that such a longlasting stimulus-165-minute half-life in humans (Desager, Golnez, De-Buck, \& Horsmans, 2002)—might also be conceptualized as a modulatory context that sets the occasion for nicotine-conditioned associations. Conceptualizing ethanol and/or nicotine as a modulatory context might help to flesh out the details of this interaction and help explain some inconsistencies in conditioning accounts (e.g., Burton \& Tiffany, 1997; Sayette, 2002). For example, how do purportedly "neutral" cues change when copresented with ethanol? If these presumed neutral cues were associat- ed with another rewarding outcome, could alcohol promote cue reactivity? That is, could the ethanol drug state transfer its conditional control to stimuli with which it has never been paired in the past? Given the appropriate stimulus arrangements, current associative theories and our research would answer a strong yes to this question (Bouton, 1993, 2002; Palmatier, 2004).

Undeniably, the investigation of associative learning processes involving nicotine has advanced our understanding of nicotine, learning, and tobacco addiction. One responsibility of preclinical researchers is to continue to develop and study behavioral models that reflect the environmental complexity and stimulus conditions encountered by the individuals they aspire to help. Although we have focused on nicotine and compulsive tobacco use, at least some of the extensions of associative learning theory that we have described in the present review should apply to compulsive drug use in general. Thus, a complete understanding of compulsive drug use will require knowledge of the unconditional stimulus and reinforcing effects of a drug, as well as their ability to function as conditional stimuli and modulators.

\section{NOTE}

1. It is important to note that the transport carts were used every day of the experiment to move the rats from the colony to the experimental room and then back. Thus, any explanation based on disruption of activity by placement in the transport cart is strained by the familiarity of the cart32 exposures before the start of Phase 2 .

\section{REFERENCES}

Alessi, S. M., Roll, J. M., Reilly, M. P., \& Johanson, C.-E. (2002). Establishment of a diazepam preference in human volunteers following differential-conditioning history of placebo versus diazepam choice. Experimental and Clinical Psychopharmacology, 10, 77-83.

Berridge, K. C., \& Robinson, T. E. (2003). Parsing reward. Trends in Neuroscience, 26, 507-513.

Besheer, J., Palmatier, M. I., Metschke, D. M., \& Bevins, R. A. (2004). Nicotine as a signal for the presence or absence of sucrose reward: A Pavlovian drug appetitive conditioning preparation in rats. Psychopharmacology, 172, 108-117.

Bevins, R. A., \& Ayres, J. J. B. (1995). One-trial context fear conditioning as a function of the interstimulus interval. Animal Learning E Behavior, 23, 400-410.

Bevins, R. A., Besheer, J., \& Pickett, K. S. (2001). Nicotine-conditioned locomotor activity in rats: Dopaminergic and GABAergic influences on conditioned expression. Pharmacology Biochemistry and Behavior, 68, 135-145.

Bevins, R. A., Eurek, S., \& Besheer, J. (in press). Timing of conditioned response in a nicotine locomotor conditioning preparation: Manipulations of the temporal arrangement between context cues and drug administration. Manuscript submitted for publication.

Bevins, R. A., Jensen, H. C., Hinze, T. S., \& Besheer, J. (1999). Taste quality and extinction of a conditioned taste aversion in rats. Animal Learning E Behavior, 27, 358-366.

Bevins, R. A., \& Palmatier, M. I. (2003). Nicotine-conditioned locomotor sensitization in rats: Assessment of the US-preexposure effect. Behavioural Brain Research, 143, 65-74. 
Boakes, R. A. (1977). Performance on learning to associate a stimulus with positive reinforcement. In H. Davis \& H. M. B. Hurwitz (Eds.), Operant-Pavlovian interactions (pp. 67-101). Hillsdale, NJ: Lawrence Erlbaum.

Bouton, M. E. (1991). Context and retrieval in extinction and in other examples of interference in simple associative learning. In L. Dachowski \& C. F. Flaherty (Eds.), Current topics in animal learning: Brain, emotion, and cognition (pp. 25-53). Hillsdale, NJ: Lawrence Erlbaum.

Bouton, M. E. (1993). Context, time, and memory retrieval in the interference paradigms of Pavlovian learning. Psychological Bulletin, 114, 80-99.

Bouton, M. E. (2002). Context, ambiguity, and unlearning: Sources of relapse after behavioral extinction. Biological Psychiatry, 52, 976986.

Brandon, T. H., Tiffany, S. T., Obremski, K. M., \& Baker, T. B. (1990). Postcessation cigarette use: The process of relapse. Addictive Behaviors, 15, 105-114.

Brooks, D. C., \& Bouton, M. E. (1993). A retrieval cue for extinction attenuates spontaneous recovery. Journal of Experimental Psychology: Animal Behavior Processes, 19, 77-89.

Burton, S. M., \& Tiffany, S. T. (1997). The effect of alcohol consumption on the craving to smoke. Addiction, 92, 15-26.

Caggiula, A. R., Donny, E. C., White, A. R., Chaudhri, N., Booth, S., Gharib, M. A., et al. (2001). Cue dependency of nicotine self-administration and smoking. Pharmacology Biochemistry and Behavior, 70,515-530.

Caggiula, A. R., Donny, E. C., White, A. R., Chaudhri, N., Booth, S., Gharib, M. A., et al. (2002). Environmental stimuli promote the acquisition of nicotine self-administration in rats. Psychopharmacology, 163, 230-237.

Caggiula, A. R., Epstein, L. H., Antelman, S. M., Saylor, S. S., Perkins, K. A., Knopf, S., et al. (1991). Conditioned tolerance to the anorectic and corticosterone-elevating effects of nicotine. Pharmacology Biochemistry and Behavior, 40, 53-59.

Carmody, T. P. (1990). Preventing relapse in the treatment of nicotine addiction: Current issues and future directions. Journal of Psychoactive Drugs, 22, 211-238.

Carter, B. L., \& Tiffany, S. T. (1999). Meta-analysis of cue-reactivity in addiction research. Addiction, 94,327-340.

Centers for Disease Control and Prevention. (n.d.). Prevalence of current cigarette smoking among adults and changes in prevalence of current and some day smoking: United States, 1996-2001. Annual smoking-attributable mortality, years of potential life lost, and economic costs-United States, 1995-1999. Retrieved from http:// www.cdc.gov/tobacco/data.htm

Clarke, P. B. S., \& Kumar, R. (1983). The effects of nicotine on locomotor activity in tolerant and non-tolerant rats. British Journal of Pharmacology, 78, 329-337.

Conners, C. K., Levin, E. D., Sparrow, E., Hinton, S. C., Erhardt, D., Meck, W. H., et al. (1996). Nicotine and attention in adult attention deficit hyperactivity disorder (ADHD). Psychopharmacology Bulletin, 32, 67-73.

Crombag, H. S., Shaham, Y. (2002). Renewal of drug seeking by contextual cues after prolonged extinction in rats. Behavioral Neuroscience, 116, 169-173.

Cunningham, C. L., Okorn, D. M., \& Howard, C. E. (1997). Interstimulus interval determines whether ethanol produces conditioned place preference or aversion in mice. Animal Learning $\mathcal{\sigma} B e-$ havior, 25, 21-42.

Cyran, J. F., Bruijnzeel, A. W., Skjei, K. L., \& Markou, A. (2003). Bupropion enhanced brain reward function and reverses the affective and somatic aspects of nicotine withdrawal in the rat. Psychopharmacology, 168, 347-358.

Dadds, M. R., Bovbjerg, D., Redd, W., \& Cutmore, T. (1997). Imagery in human classical conditioning. Psychological Bulletin, 122, 89-103. de Fiebre, N. C., Dawson, R., Jr., \& de Fiebre, C. M. (2002). The selectively bred high alcohol sensitivity (HAS) and low alcohol sensitivity (LAS) rats differ in sensitivity to nicotine. Alcohol: Clinical and Experimental Research, 26, 765-772.

Desager, J. P., Golnez, J. L., De-Buck, C., \& Horsmans, Y. (2002). Watercress has no importance for the elimination of ethanol by CYP2E1 inhibition. Pharmacology and Toxicology, 91, 103-105.

DiChiara, G. (1995). The role of dopamine in drug abuse viewed from the perspective of its role in motivation. Drug and Alcohol Dependence, 38, 95-137.

Donahoe, J. W., \& Vegas, R. (2004). Pavlovian conditioning: The CSUR relation. Journal of Experimental Psychology: Animal Behavior Processes, 30, 17-33.

Donny, E. C., Chaudhri, N., Caggiula, A. R., Evans-Martin, F. F., Booth, S., Gharib, M. A., et al. (2003). Operant responding for a visual reinforcer in rats is enhanced by noncontingent nicotine: Implications for nicotine self-administration and reinforcement. Psychopharmacology, 169, 68-76.

Dwoskin, L. P., Crooks, P. A., Teng, L., Green, T. A., \& Bardo, M. T. (1999). Acute and chronic effects of nornicotine on locomotor activity in rats: Altered response to nicotine. Psychopharmacology, 145, 442-451.

Emmons, K. M., Wechsler, H., Dowdall, G., \& Abraham, M. (1998). Predictors of smoking among US college students. American Journal of Public Health, 88, 104-107.

Epstein, L. H., Caggiula, A. R., \& Stiller, R. (1989). Environmentspecific tolerance to nicotine. Psychopharmacology, 97, 235-237.

Farwell, B. J., \& Ayres, J. J. B. (1979). Stimulus-reinforcer and response-reinforcer relations in the control of conditioned appetitive headpoking ("goal tracking") in rats. Learning and Motivation, 10, 295-312.

Federal Trade Commission. (2001). For the consumer. Retrieved from http://www.ftc.gov/reports/cigarettes/1999

File, S. E., Cheeta, S., Irvine, E. E., Tucci, S., \& Akthar, M. (2002). Conditioned anxiety to nicotine. Psychopharmacology, 164, 309-317.

Fisher, E. B., Lichtenstein, E., Haire-Joshu, D., Morgan, G. D., \& Rehberg, H. R. (1993). Methods, successes, and failures of smoking cessation programs. Annual Review of Medicine, 44, 481-513.

Fudala, P. J., \& Iwamoto, E. T. (1986). Further studies on nicotine-induced conditioned place preference in the rat. Pharmacology Biochemistry and Behavior, 25, 1041-1049.

Garrett, B. E., Rose, C. A., \& Henningfield, J. E. (2001). Tobacco addiction and pharmacological interventions. Expert Opinion on Pharmacotherapy, 2, 1545-1555.

Geier, A., Mucha, R. F., \& Pauli, P. (2000). Appetitive nature of drug cues confirmed with physiological measures in a model using pictures of smoking. Psychopharmacology, 150, 283-291.

Glover, E. D., \& Glover, P. N. (2001). Pharmacologic treatments for the nicotine dependent smoker. American Journal of Health Behavior, 25, 179-182.

Greeley, J., Lê, D. A., Poulos, C. X., \& Cappell, H. (1984). Alcohol is an effective cue in the conditioned control of tolerance to alcohol. Psychopharmacology, 83, 159-162.

Harris, J. E. (1980). Cigarette smoking among successive birth cohorts of men and women in the United States during 1900-80. Journal of the National Cancer Institute, 71, 473-479.

Hays, J. T., \& Ebbert, J. O. (2003). Bupropion sustained release for treatment of tobacco dependence. Mayo Clinic Proceedings, 78, 1020-1024.

Henningfield, J. E., Schuh, L. M., \& Jarvik, M. E. (1995). Pathophysiology of tobacco dependence. In: F. E. Bloom \& D. J. (Eds.), Psychopharmacology: The fourth generation of progress (pp. 1715-1729). New York: Raven Press.

Hirschborn, I. D., \& Rosecrans, J. A. (1974). Studies on the time course and the effect of cholinergic and adrenergic receptor blockers on the stimulus effect of nicotine. Psychopharmacologia, 40, 109-120. 
Holland, P. C. (1999). Intertrial interval effects in Pavlovian serial feature positive discriminations. Animal Learning \& Behavior, 27, 127139.

Hughes, J. R. (1995). Clinical implications of the association between smoking and alcoholism. In J. B. Fertig \& J. P. Allen (Eds.), Alcohol and tobacco: From basic science to clinical practice (NIAAA Research Monograph 30, pp. 171-181). Washington, DC: Government Printing Office.

Hughes, J. R., Goldstein, M. G., Hurt, R. D., \& Shiffman, S. (1999). Recent advances in the pharmacotherapy of smoking. Journal of the American Medical Association, 281, 72-76.

Iwamoto, E. T., \& Williamson, E. C. (1984). Nicotine-induced taste aversion: Characterization and preexposure effects in rats. Pharmacology Biochemistry and Behavior, 21, 527-532.

Kasprow, W. J., Schachtman, T. R., \& Miller, R. R. (1987). The comparator hypothesis of conditioned response generation: Manifest conditioned excitation and inhibition as a function of relative excitatory strengths of CS and conditioning context at the time of testing. Journal of Experimental Psychology: Animal Behavior Processes, 13, 395-406.

Kim, J. A., Siegel, S., \& Patenall, V. R. A. (1999). Drug-onset cues as signals: Intraadministration associations and tolerance. Journal of Experimental Psychology: Animal Behavior Processes, 25, 491-504.

Koob, G. F. (2004). Allostatic view of motivation: Implications for psychopathology. In: R. A. Bevins \&M. T. Bardo (Eds.), Nebraska symposium on motivation, 50, motivational factors in the etiology of drug abuse (pp. 1-18). Lincoln: University of Nebraska Press.

Larsson, A., \& Engel, J. A. (2004). Neurochemical and behavioral studies on ethanol and nicotine interactions. Neuroscience and Biobehavioral Reviews, 27, 713-720.

Lazev, A. B., Herzog, T. A., \& Brandon, T. H. (1999). Classical conditioning of environmental cues to cigarette smoking. Experimental and Clinical Psychopharmacology, 7, 56-63.

Learned-Coughlin, S. M., Bergström, M., Savitcheva, I., Ascher, J., Schmith, V. D., \& Långstrom, B. (2003). In vivo activity of bupropion at the human dopamine transporter as measured by positron emission tomography. Biological Psychiatry, 54, 800-805.

Lee, J. H., Ku, J., Kim, K., Kim, B., Kim, I. Y., Yang, B. H., et al. (2003). Experimental application of virtual reality for nicotine craving through cue exposure. CyberPsychology \& Behavior, 6, 275-280.

Le Foll, B., Schwartz, J.-C., \& Sokoloff, P. (2003). Disruption of nicotine conditioning by dopamine D3 receptor ligands. Molecular Psychiatry, 8, 225-230.

Li, S. I., Perry, K. W., \&Wong, D. T. (2002). Influence of fluoxetine on the ability of bupropion to modulate extracellular dopamine and norepinephrine concentrations in three mesocorticolimbic areas of rats. Neuropharmacology, 42, 181-190.

Martin, G. M., Gans, M., \& van der Kooy, D. (1990). Discriminative properties of morphine that modulate associations between tastes and lithium chloride. Journal of Experimental Psychology: Animal Behavior Processes, 16, 56-68.

McDonald, R. V., \& Siegel, S. (2004). Intra-administration associations and withdrawal symptoms: Morphine-elicited morphine withdrawal. Experimental \& Clinical Psychopharmacology, 12, 3-11.

Miller, M. A., Parker, K., Keely, J. P., Johnson, J. L., \& Schaal, D. W. (2002). Searching for evidence of transfer between drug facilitators. Learning \& Motivation, 33, 197-229.

Miller, R. R., \& Oberling, P. (1998). Analogies between occasion setting and Pavlovian conditioning. In P. C. Holland \& N. A. Schmajuk (Eds.), Occasion setting: Associative learning and cognition in animals (pp. 3-35). Washington, DC: American Psychological Association.

Niaura, R. S., Abrams, D. B., Shadel, W. G., Rohsenow, D. J., Monti, P. M., \& Sirota, A. D. (1999). Cue exposure treatment for smoking relapse prevention: A controlled clinical trial. Addiction, 94, 685695.
O’Brien, C. P., Childress, A. R., McLellan, A. T., \& Ehrman, R. (1992). A learning model for addiction. In C. P. O’Brien \& J. H. Jaffe (Eds.), Addictive states (pp. 157-177). New York: Raven Press.

Olausson, P., Jentsch, J. D., \& Taylor, J. R. (2003). Repeated nicotine exposure enhances reward-related learning in the rat. Neuropsychopharmacology, 28, 1264-1271.

Olausson, P., Jentsch, J. D., \& Taylor, J. R. (2004a). Nicotine enhances responding with conditioned reinforcement. Psychopharmacology, 173, 98-104.

Olausson, P., Jentsch, J. D., \& Taylor, J. R. (2004b). Repeated nicotine exposure enhances responding with conditioned reinforcement. Psychopharmacology, 173, 173-178.

Owens, J. C., Balogh, S. A., McClure-Begley, T. D., Butt, C. M., Labarca, C., \& Lester, H. A., et al. (2003). Alpha4beta2* nicotinic acetylcholine receptors modulate the effects of ethanol and nicotine on the acoustic startle response. Alcohol: Clinical and Experimental Research, 27, 1867-1875.

Palmatier, M. I. (2004). Drug modulators in appetitive Pavlovian conditioning. Dissertation Abstracts International.

Palmatier, M. I., \& Bevins, R. A. (2002). Examination of SCH-23390, eticlopride, and baclofen on acquisition of nicotine-conditioned hyperactivity in rats. Neuropsychobiology, 45, 87-94.

Palmatier, M. I., Fung, E. Y. K., \& Bevins, R. A. (2003). Effects of chronic caffeine preexposure on the conditioned and unconditioned psychomotor activity induced by nicotine and amphetamine in rats. Behavioural Pharmacology, 14, 191-198.

Palmatier, M. I., Peterson, J. L., Wilkinson, J. L., \& Bevins, R. A. (2004). Nicotine serves as a feature-positive modulator of Pavlovian appetitive conditioning in rats. Behavioural Pharmacology, 15, 183-194.

Palmatier, M. I., Wilkinson, J. L., \& Bevins, R. A. (2004, in press). Stimulus properties of nicotine, amphetamine, and chlordiazepoxide as positive features in a Pavlorian appetitive discrimination task in rats. Neuropsychopharmacology.

Panksepp, J., Nocjar, C., Burgdorf, J., Panksepp, J. B., \& Huber, R. (2004). The role of emotional systems in addiction: A neuroethological perspective. In R. A. Bevins \& M. T. Bardo (Eds.), Nebraska symposium on motivation, 50, motivational factors in the etiology of drug abuse (pp. 85-126). Lincoln: University of Nebraska Press.

Parker, L. A. (1995). Rewarding drugs produce taste avoidance, but not taste aversion. Neuroscience and Biobehavioral Reviews, 19, 143-157.

Pavlov, I. P. (1927). Conditioned reflexes. New York: Dover.

Perkins, K. A., DiMarco, A., Grobe, J. E., Scierka, A., \& Stiller, R. L. (1994). Nicotine discrimination in male and female smokers. Psychopharmacology, 116, 407-413.

Pritchard, W. S., Robinson, J. H., Guy, T. D., Davis, R. A., \& Stiles ,M. F. (1996). Assessing the sensory role of nicotine in cigarette smoking. Psychopharmacology, 127, 55-62.

Raw, M., \& Russell, M. A. H. (1980). Rapid smoking, cue exposure and support in the modification of smoking. Behavioural Research E Therapy, 18, 363-372.

Reid, M. S., Ho, L. B., \& Berger, S. P. (1996). Effects of environmental conditioning on the development of nicotine sensitization: Behavioral and neurochemical analysis. Psychopharmacology, 126, 301-310.

Reid, M. S., Ho, L. B., \& Berger, S. P. (1998). Behavioral and neurochemical components of nicotine sensitization following 15day pretreatment: Studies on contextual conditioning. Behavioural Pharmacology, 9, 137-148.

Reilly, S., \& Revusky, S. (1992). Drug-drug heart rate conditioning in rats: Effective USs when pentobarbital is the CS. Pharmacology Biochemistry and Behavior, 42, 633-643.

Rescorla, R. A. (1986). Facilitation and excitation. Journal of Experimental Psychology: Animal Behavior Processes, 12, 325-332.

Revusky, S., Coombes, S., \& Pohl, R. W. (1982). Drug states as discriminative stimuli in a flavor-aversion learning experiment. Journal of Comparative and Physiological Psychology, 96, 200-211. 
Revusky, S., Davey, V., \& Zagorski, M. (1989). Heart rate conditioning with pentobarbital as a conditioned stimulus and amphetamine as an unconditioned stimulus. Behavioral Neuroscience, 103, 296-307.

Revusky, S., \& Reilly, S. (1990). Dose effects on heart rate conditioning when pentobarbital is the CS and amphetamine in the US. Pharmacology Biochemistry and Behavior, 36, 933-936.

Robbins, S. J. (1990). Mechanisms underlying spontaneous recovery in autoshaping. Journal of Experimental Psychology: Animal Behavior Processes, 16, 235-249.

Robinson, T. E., \& Berridge, K. C. (1993). The neural basis of drug craving: An incentive-sensitization theory of addiction. Brain Research Reviews, 18, 247-291.

Rose, J. E., Behm, F. M., \& Levin, E. D. (1993). Role of nicotine dose and sensory cues in the regulation of smoke intake. Pharmacology Biochemistry and Behavior, 44, 891-900.

Rose, J. E., \& Levin, E. D. (1991). Inter-relationships between conditioned and primary reinforcement in the maintenance of cigarette smoking. British Journal of Addiction, 86, 605-609.

Sanderson, S. D., Vennerstrom, J. L., Cheruku, S. R., Padmanilayam, M. P., Thiele, G. M., Palmatier, M. I., et al. (2003). Active immunization against nicotine with a peptide vaccine composed of a conformationally biased agonist of $\mathrm{C} 5 \mathrm{a}$ as a molecular adjuvant. International Immunopharmacology, 3, 137-146.

Sayette, M. (2002). The effects of alcohol on cigarette craving. Alcohol: Clinical and Experimental Research, 26, 1925-1927.

Schechter, M. D., \& Rosecrans, J. A. (1972). Nicotine as a discriminative cue in rats: Inability of related drugs to produce a nicotine-like cueing effect. Psychopharmacologia, 27, 379-387.

Schmajuk, N. A., Lamoureux, J. A., \& Holland, P. C. (1998). Occasion setting: A neural network approach. Psychological Review, 105, 3-32.

Schroeder, B. E., Binzak, J. M., \& Kelley, A. E. (2001). A common profile of prefrontal cortical activation following exposure to nicotineor chocolate-associated contextual cues. Neuroscience, 105, 535-545.

Shiffman, S. (1986). A cluster-analytic classification of smoking relapse episodes. Addictive Behaviors, 11, 295-307.

Shiffman, S., Fischer, L. A., Paty, J. A., Gnys, M., Hickox, M., \& Kassel, J. D. (1994). Drinking and smoking: A field study of their association. Annals of Behavioral Medicine, 16, 203-209.

Shoaib, M., Stolerman, I. P., \&Kumar, R. C. (1994). Nicotine-induced place preferences following prior nicotine exposure in rats. Psychopharmacology, 113, 445-452.

Siegel, S., \& Ramos, B. M. C. (2002). Applying laboratory research: Drug anticipation and the treatment of drug addiction. Experimental and Clinical Psychopharmacology, 10, 162-183.

Skinner, D. M., Goddard, M. J., \& Holland, P. C. (1998). What can nontraditional features tell us about conditioning and occasion setting? In P. C. Holland \& N. A. Schmajuk (Eds.), Occasion setting: Associative learning and cognition in animals (pp. 113-144). Washington, DC: American Psychological Association.

Smith, M. C., Coleman, S. R., \& Gormezano, I. (1969). Classical conditioning of the rabbit's nictitating membrane response at backward, simultaneous, and forward CS-US intervals. Journal of Comparative and Physiological Psychology, 69, 226-231.
Sokolowska, M., Siegel, S., \& Kim, J. A. (2002). Intraadministration associations: Conditional hyperalgesia elicited by morphine onset cues. Journal of Experimental Psychology: Animal Behavior Processes, $28,309-320$.

Stewart, J. (2004). Pathways to relapse: Factors controlling the reinitiation of drug seeking after abstinence. In R. Bevins \& M. T. Bardo (Eds.), Nebraska symposium on motivation, 50, motivational factors in the etiology of drug abuse (pp. 197-234). Lincoln: University of Nebraska Press.

Stolerman, I. P. (1989). Discriminative stimulus effects of nicotine in rats trained under different schedules of reinforcement. Psychopharmacology, 97, 131-138.

Stolerman, I. P., Fink, R., \& Jarvik, M. E. (1973). Acute and chronic tolerance to nicotine measured by activity in rats. Psychopharmacologia, 30, 329-342.

Stolerman, I. P., Garcha, H. S., Pratt, J. A., \& Kumar, R. (1984). Role of training dose in discrimination of nicotine and related compounds by rats. Psychopharmacology, 84, 413-419.

Swan, G. E., McAfee, T., Curry, S. J., Jack, L. M., Javitz, H., Dacey, S., et al. (2003). Effectiveness of bupropion sustained release for smoking cessation in a health care setting: A randomized trial. Archives of Internal Medicine, 163, 2337-2344.

Swartzentruber, D. (1998). Perspectives on modulation: Modulator and target-focused views. In P. C. Holland \& N. A. Schmajuk (Eds.), Occasion setting: Associative learning and cognition in animals( pp. 167-197). Washington, DC: American Psychological Association.

Timberlake, W., \& Lucas, G. A. (1989). Behavior systems and learning: From misbehavior to general principles. In S. B. Klein \& R. R. Mower (Eds.), Contemporary learning theories: Instrumental conditioning theory and the impact of biological constraints on learning (pp. 237-275). Hillsdale, NJ: Lawrence Erlbaum.

Tomar, S. L., \& Giovino, G. A. (1998). Incidence and predictors of smokeless tobacco use among US youth. American Journal of Public Health, 88, 20-26.

Tucci, S., Cheeta, S., Genn, R. F., Seth, P., \& File, S. E. (2002). Anxiety conditioned to nicotine in the elevated plus-maze is time dependent. Behavioural Pharmacology, 13, 615-620.

Tyndale, R. F., \&Sellers, E. M. (2001). Variable CYP2A6-mediated nicotine metabolism alters smoking behavior and risk. Drug $\mathrm{Me}-$ tabolism and Disposition, 29, 548-552.

Walter, S., \& Kuschinsky, K. (1989). Conditioning of nicotine effects on motility and behaviour in rats. Naunyn-Schmiedeberg's Archives of Pharmacology, 339, 208-213.

Wasserman, E. A., \& Miller, R. R. (1997). What's elementary about associative learning? Annual Review of Psychology, 48, 573-607.

Wise, R. A. (2004). Drive, incentive, and reinforcement: The antecedents and consequences of motivation. In R. A. Bevins \& M. T. Bardo (Eds.), Motivational factors in the etiology of drug abuse. Lincoln: University of Nebraska Press.

Wise, R. A., \& Bozarth, M. A. (1987). A psychomotor stimulant theory of addiction. Psychological Revierw, 94, 469-492. 